\title{
Pengaruh Kualitas Pelayanan Terhadap Kepuasan Nasabah Tabungan Unit Usaha Syariah Bank Jambi
}

\author{
Susilawati, Pupu Sopini \\ Fakultas Ekonomi Universitas Batanghari \\ Correspondence email: susilawati@unbari.ac.id
}

\begin{abstract}
The purpose of this study is to analyze the quality of service and satisfaction levels of savings customers of Bank Jambi's Sharia Business Unit and analyze the effect of service quality on the satisfaction of savings customers of Bank Jambi's Sharia Business Unit both simultaneously and partially. The selection of Bank Jambi Sharia Business Unit as an object of research because Bank Jambi is a regional bank that should host in its own area, but in its business operations must still prioritize service to customers in the face of many competitors in Jambi City, including Islamic banking. The research method used is a quantitative descriptive anaisis with a population of all savings customers of Bank Jambi's Sharia Business Unit in 2020 which amounted to 23,220 accounts (people). The sample withdrawal method uses the Slovin Formula with the results of calculations as many as 100 respondents. Based on the results of primary data research for service quality free variables, service quality variables produced the highest score on compliance variables of 449.5. This shows that the management of Bank Jambi's Sharia Business Unit is able to meet Islamic law and operate under the principles of Islamic economics and banking in serving its customers. While the lowest score of 419.25 is in the Reliability variable, but this score is still in the scale range with a very good category. As for the customer satisfaction variable, the average score of 442.75 from the respondents' responses with categories was very satisfied. Based on the results of the hypothesis test, from the results of data processing it is known that sig value. $0.000<0.05$ (significance level) which means that simultaneously the free variable has a significant effect on customer satisfaction of Bank Jambi's Sharia Business Unit. The regression coefficient value of the six free variables used is known that the empathy variable has the largest regression coefficient which is 0.335. This shows that the empathy variable has the most influence on customer satisfaction savings of Bank Jambi's Sharia Business Unit. While the physical proof variable has the smallest regression coefficient of - 0.128. This means that physical facilities are not the dominant factor in determining the level of customer satisfaction in using banking services at Bank Jambi's Sharia Business Unit.
\end{abstract}

Keywords: Quality of Service, Customer Satisfaction

\section{Pendahuluan}

Keberhasilan sebuah organisasi dalam merealisasikan tujuannya ditentukan oleh kemampuan organisasi bersangkutan dalam mengidentifikasi kebutuhan dan keinginan pasar sasarannya dan memberikan kepuasan yang diharapkan secara lebih efektif dan efisien daripada para pesaingnya. Salah satu cara yang dapat digunakan untuk memuaskan konsumen adalah dengan memberikan pelayanan yang baik. Kualitas pelayanan dalam perusahaan sangatlah penting karena sebagai penggerak utama seluruh kegiatan atau aktivitas perusahaan dalam upaya mencapai tujuannya, baik untuk memperoleh keuntungan maupun untuk mempertahankan kelangsungan hidup perusahaan. Berhasil tidaknya suatu perusahaan dalam mempertahankan kegiatannya dimulai dari mempertahankan perusahaan dalam meningkatkan kinerja secara maksimal. Kualitas pelayanan berpusat pada upaya pemenuhan kebutuhan dan keinginan pelanggan serta ketetapan penyampaiannya untuk mengimbangi harapan pelanggan. Dengan pelayanan yang baik, diharapkan masyarakat akan merasa dihargai dan tidak merasa diabaikan haknya yang nantinya akan mengakibatkan masyarakat sebagai pelanggan akan pindah ke perusahaan yang lain. Kualitas pelayanan memang memegang peran penting untuk mencapai tingkat kepuasan pelanggan.

Citra kualitas pelayanan yang baik bukanlah menjadi sudut pandang atau presepsi pihak perusahaan, melainkan berdasarkan sudut pandang dari pelanggan, karena dalam hal ini pelanggan yang merasa dan menikmati pelayanan dari perusahaan. Presepsi pelanggan terhadap kualitas pelayanan merupakan penilaian menyeluruh atas keunggulan suatu jasa atau produk. Unit Usaha Syariah Bank Jambi merupakan salah satu unit usaha Bank Jambi yang bergerak dibidang bisnis perbankan syariah. Visi Unit Usaha Syariah Bank Jambi adalah menjadi bank umum syariah terkemuka di Provinsi Jambi, berdaya saing tinggi yang tumbuh secara sehat dan handal melayani mitra usaha. Adapun salah satu misi Unit Usaha Syariah Bank Jambi adalah mengembangkan pasar perbankan syariah di wilayah Provinsi Jambi. Untuk mewujudkan visi dan misi tersebut Unit Usaha Syariah Bank Jambi terus berupaya meningkatkan kualitas pelayanan kepada nasabahnya. Selama lima tahun terakhir jumlah nasabah Unit Usaha Syariah Bank Jambi, khususnya nasabah tabungan terus mengalami peningkatan sebagaimana terlihat pada Tabel 1 berikut : 
Susilawati dan Pupu Sopini, Pengaruh Kualitas Pelayanan Terhadap Kepuasan Nasabah Tabungan Unit Usaha Syariah Bank Jambi

Tabel 1

Jumlah Nasabah Tabungan Unit Usaha Syariah Bank Jambi Tahun 2016 - 2020 (orang)

\begin{tabular}{|c|c|c|c|c|c|c|}
\hline \multirow{3}{*}{ Tahun } & \multicolumn{6}{|c|}{ Jenis Tabungan } \\
\hline & \multicolumn{2}{|c|}{ Siginjai Ib } & \multirow{2}{*}{ Tabunganku } & \multirow{2}{*}{$\begin{array}{c}\text { Niat Haji } \\
\text { Mudharabah }\end{array}$} & \multirow{2}{*}{ Total } & \multirow{2}{*}{ Perkembangan (\%) } \\
\hline & Mudharabah & Wadiah & & & & \\
\hline 2016 & 3.034 & 111 & 454 & 332 & 3.931 & - \\
\hline 2017 & 8.339 & 177 & 627 & 389 & 9.532 & 142,48 \\
\hline 2018 & 9.334 & 525 & 801 & 477 & 11.137 & 16,84 \\
\hline 2019 & 10.866 & 1.205 & 931 & 510 & 13.512 & 21,33 \\
\hline 2020 & 17.139 & 2.875 & 1.064 & 2.142 & 23.220 & 71,85 \\
\hline
\end{tabular}

Sumber : Unit Usaha Syariah Bank Jambi, 2021

Tabel 1 terlihat bahwa selama lima tahun terakhir jumlah nasabah tabungan Unit Usaha Syariah Bank Jambi mengalami peningkatan. Persentase peningkatan tertinggi terjadi pada tahun 2017 sebesar 142,48\%. Pada tahun berikutnya jumlah nasabah terus mengalami peningkatan dengan persentase perkembangan yang berfluktuasi meningkat sampe tahun 2020. Peningkatan jumlah nasabah ini perlu terus dipertahankan mengingat semakin banyaknya pesaing yang tidak hanya berasal dari sesama bank syariah, tetapi juga dari bank konvensional. Untuk menghadapi persaingan tersebut Unit Usaha Syariah Bank Jambi harus terus berupaya meningkatkan kualitas pelayanannya agar dapat mempertahankan nasabah yang ada dan dapat menarik nasabah baru. Hal ini hanya akan tercapai jika pihak Unit Usaha Syariah Bank Jambi dapat memberikan kepuasan kepada nasabah yang dilayani.

\section{Landasan Teori}

Model Carter adalah sebuah instrumen yang dapat digunakan untuk mendefinisikan dan mengukur layanan kualitas perbankan islam dan berguna sebagai alat penilaian kualitas. Mekanisme pengukuran metode Carter sama dengan Servqual, hanya saja dalam metode Carter ditambahkan dimensi compliance (pemenuhan prinsip dan hukum islam) sehingga ada 6 dimensi yaitu: compliance, assurance, reliability, tangible, empathy, dan responsiveness, yang secara keseluruhan terdiri dari 34 item. Keenam dimensi tersebut dijabarkan lebih lanjut Fauzi (2016) sebagai berikut: (1) Compliance, yang berarti kemampuan untuk memenuhi hukum islam dan beroperasi dibawah prinsip-prinsip ekonomi dan perbankan islam; (2) Assurance, pengetahuan dan kesopanan karyawan dan kemampuan mereka memberikan rasa aman dan percaya kepada pelanggan. Hal tersebut juga termasuk komunikasi secara verbal dan tulisan antara karyawan dan pelanggan; (3) Reliability, kemampuan untuk memiliki performa layanan yang dijanjikan, dapat diandalkan dan akurat; (4) Tangible, aspek yang terlihat secara fisik misal peralatan, personel, dan bahan bahan komunikasi; (5) Emphaty, kemampuan personel untuk peduli dan memberikan perhatian secara individu kepada pelanggan; dan (6) Responsiveness, keinginan untuk membantu pelanggan dan memberikan layanan yang cepat.

Menurut Ali (2008) Kepuasan pelanggan merupakan fungsi dasar dari sejemlah value produk (kinerja) yang dipersepsikan oleh pelanggan dibandingkan dengan harapan pelanggan sebelum menggunakan. Dimensi pembentukan kepuasan konsumen terdiri dari (1) konfirmasi harapan; (2) minat pembelian ulang; dan (3) kesediaan untuk merekomendasi

\section{Metode}

Metode penelitian yang digunakan dalam penelitian ini adalah anaisis deskriptif kuantitatif dengan populasi seluruh jumlah nasabah tabungan Unit Usaha Syariah Bank Jambi pada tahun 2020 yang berjumlah 23.220 account (orang). Metode penarikan sampel menggunakan Rumus Slovin dengan hasil perhitungan sebanyak 100 orang responden. Jenis data yang digunakan dalam penelitian ini adalah data primer dan data sekunder, baik berupa kualitatif maupun kuantitatif. Metode analisis deskriptif diperoleh dari nasabah Unit Usaha Syariah Bank Jambi yang menjadi responden penelitian sebagai dengan mengisi kuisioner berbentuk pernyataan tertutup dimana alternatif jawabannya telah tersedia dari 1-5.

Tabel 2

Skala Likert

\begin{tabular}{|l|c|c|}
\hline Sangat tidak baik/Sangat tidak puas & STS / STP & Skor 1 \\
\hline Tidak baik/Tidak puas & TS / TP & Skor 2 \\
\hline Cukup Baik/Cukup Puas & CB / CP & Skor 3 \\
\hline Baik/Puas & B / P & Skor 4 \\
\hline Sangat Baik/Sangat Puas & SB / SP & Skor 5 \\
\hline
\end{tabular}

Sumber: Sugiyono (2011)

Untuk menganalisis permasalahan diatas digunakan skala penelitian dengan menghitung frekuensi skor setiap item pertanyaan. Menurut Sugiyono (2011) bahwa perhitungan skor setiap komponen yang diteliti dengan mengalikan seluruh frekuensi data dengan nilai bobot. Rumus yang digunakan adalah: 
1. Penentuan Rentang Skor

Rentang skor terendah $=$ Bobot terendah $\times$ Jumlah sampel $=1 \times 100=100$

Rentang skor tertinggi $=$ Bobot tertinggi $\times$ Jumlah sampel $=5 \times 100=500$

2. Penentuan Rentang Skala

Rentang skala $R S=\frac{\mathrm{n}(\mathrm{m}-1)}{\mathrm{m}}$

Dimana : $\mathrm{n}=$ Jumlah Sampel; $\mathrm{m}=$ Jumlah alternatif jawaban

3. $R S=\frac{100(5-1)}{5}=80$

Maka: 100 - 179,9 = Sangat Tidak Baik/Sangat Tidak Puas; 180 - 259,9 = Tidak Baik / Tidak Puas; 260 - 339,9 = Cukup Baik/Cukup Puas; 340 - 419,9 = Baik / Puas; 420 - 500 = Sangat Baik / Sangat Puas

Analisis Kuantitatif diperoleh dengan menggunakan statistik deskriptif dan inferensial/ induktif. Peneliti menggunakan statistik inferensial bila penelitian dilakukan pada sampel yang digunakan secara random. Untuk menjawab tujuan penelitian yang ke- 2 digunakan analisis regresi linear berganda. Menurut Umar (2011) rumus persamaan regresi linear berganda :

$\hat{Y}=a+b_{1} X_{1}+b_{2} X_{2}+b_{3} X_{3}+b_{4} X_{4}+b_{5} X_{5}+b_{6} X_{6}+e$

Dimana : $\hat{Y}$ : Kepuasan Nasabah; a : Intercept; $b_{1}-b_{5}$ : Koefisien regresi; $X_{1}$ : Compliance; $X_{2}:$ Assurance' $X_{3}$ : Reliability; $\mathrm{X}_{4}$ : Tangible; $\mathrm{X}_{5}$ : Emphaty; $\mathrm{X}_{6}$ : Responsiveness; e : Error

Hasil

Tabel 3

Karakteristik Responden Berdasarkan Jenis Kelamin

\begin{tabular}{|c|c|c|}
\hline Jenis Kelamin & Jumlah (orang) & Persentase (\%) \\
\hline Laki-Laki & 49 & 49 \\
\hline Perempuan & 51 & 51 \\
\hline Jumlah & 100 & 100 \\
\hline
\end{tabular}

Sumber: data olahan

Berdasarkan tabel diatas, karakteristik responden menurut jenis kelamin terdiri dari 49 orang laki-laki atau 49 $\%$ dari jumlah sampel. Sedangkan perempuan berjumlah 51 orang atau $51 \%$ dari total sampel 100 orang.

Tabel 4

Karakteristik Responden Berdasarkan Usia

\begin{tabular}{lrr}
\hline \multicolumn{1}{c}{ Usia Nasabah (Tahun) } & Jumlah (orang) & Persentase (\%) \\
\hline$<20$ & 10 & 10 \\
$20-30$ & 29 & 29 \\
$31-40$ & 32 & 32 \\
$>40$ & 29 & 29 \\
Jumlah & 100 & 100 \\
\hline
\end{tabular}

Sumber: data olahan

Berdasarkan tabel diatas, karakteristik responden menurut usia nasabah Unit Syariah Bank Jambi terdiri dari 10 orang usia dibawah 20 tahun, 29 orang usia 20- 30 tahun, 32 orang usia 31-40 tahun dan 29 orang usia diatas 40 tahun.

Tabel 5

Karakteristik Responden Berdasarkan Pekerjaan

\begin{tabular}{lrr}
\hline \multicolumn{1}{c}{ Pekerjaan Nasabah } & Jumlah (orang) & Persentase (\%) \\
\hline PNS & 31 & 31 \\
Wiraswasta & 12 & 12 \\
TNI/POLRI & 4 & 4 \\
Pedagang & 11 & 11 \\
Ibu Rumah Tangga & 12 & 12 \\
Dan Lain-lain & 30 & 30 \\
Jumlah & 100 & 100 \\
\hline
\end{tabular}

Sumber: data olahan 
Berdasarkan tabel diatas, karakteristik responden menurut pekerjaan nasabah adalah profesi sebagai PNS sebanyak 31 orang, wiraswasta sebanyak 12 orang, TNI/Polri sebanyak 4 orang, Pedagang 11 orang, Ibu Rumah Tangga sebanyak 12 orang dan pekerjaan lainnya sebanyak 30 orang.

Tabel 6

arakteristik Responden Berdasarkan Lama Menjadi Nasabah

\begin{tabular}{lcrr}
\hline \multicolumn{2}{c}{ Lama Menjadi Nasabah (Tahun) } & Jumlah (orang) & Persentase (\%) \\
\hline$<1$ & 28 & 28 \\
$1-2$ & 29 & 29 \\
$3-4$ & 11 & 11 \\
$>3$ & 32 & 32 \\
Jumlah & 100 & 100 \\
\hline
\end{tabular}

Sumber: data olahan

Berdasarkan data tabel diatas, karakteristik responden menurut lamanya menjadi nasabah Unit Usaha Syariah Bank Jambi adalah nasabah yang kurang dari 1 tahun berjumlah 28 orang, 1-2 tahun sebanyak 29 orang, 3-4 tahun sebanyak 11 orang dan nasabah diatas 3 tahun sebanyak 32 orang dari sampel keseluruhan penelitian sebanyak 100 orang.

Tabel 7

Rekap Hasil Skor Variabel Kualitas Pelayanan dan Kepuasan Nasabah Pada Unit Usaha Syariah Bank Jambi

\begin{tabular}{|c|c|c|c|}
\hline No & Variabel & \multirow{2}{*}{ Jumlah } & \multirow{2}{*}{ Kesimpulan } \\
\hline \multicolumn{2}{|c|}{ Variabel Kualitas Pelayanan $(\mathrm{X})$ : } & & \\
\hline & Kepatuhan (Compliance) X1 & 449,50 & Sangat Baik \\
\hline 2 & Jaminan (Assurance) X2 & 436,80 & Sangat Baik \\
\hline 3 & Keandalan (Reliability) X3 & 419,25 & Sangat Baik \\
\hline 4 & Bukti Fisik (Tangible) X4 & 435,14 & Sangat Baik \\
\hline 5 & Empati (Emphaty) X5 & 441,75 & Sangat Baik \\
\hline 6 & Daya Tanggap (Responsiveness) X6 & 441,00 & Sangat Baik \\
\hline \multicolumn{2}{|c|}{ Variabel Kepuasan Nasabah (Y) } & 442,75 & Sangat Puas \\
\hline
\end{tabular}

Sumber: data olahan

Berdasarkan rekap hasil penelitian Variabel Kualitas Pelayanan menghasilkan skor tertinggi pada variabel Kepatuhan (Compliance) sebesar 449,5. Hal tersebut menunjukkan bahwa manajemen Unit Usaha Syariah Bank Jambi mampu dalam memenuhi hukum Islam dan beroperasi dibawah prinsip-prinsip ekonomi dan perbankan Islam dalam melayani nasabahnya. Sedangkan hasil skor terendah sebesar 419,25 terdapat pada variabel Keandalan (Reliability), namun hal ini hasil skor tersebut masih dalam rentang skala dengan kategori sangat baik. Hasil penelitian data primer untuk Variabel Kepuasan Nasabah menunjukkan hasil skor sebesar 442,75, artinya layanan yang diberikan Unit Usaha Syariah Bank Jambi pada nasabahnya secara umum memberikan nilai sangat puas. Dengan demikian pihak manajemen harus mempertahankan kepuasan nasabah agar tetap loyal dalam bertransaksi produk maupun jasa layanan Unit Usaha Syariah Bank Jambi.

Persamaan regresi pada Tabel 10 adalah sebagai berikut:

$\mathrm{Y}=0,254+0,141 \mathrm{X} 1+0,172 \mathrm{X} 2+0,196 \mathrm{X} 3-0,128 \mathrm{X} 4+0,335 \mathrm{X} 5+0,206 \mathrm{X} 6$

Persamaan regresi linear berganda tersebut dapat dijelaskan bahwa nilai konstanta sebesar 0,254 menunjukkan bahwa jika kualitas pelayanan tidak mengalami perubahan maka besarnya skor kepuasan nasabah tabungan Unit Usaha Syariah Bank Jambi adalah 0,254. Koefisien regresi variabel kepatuhan $\left(\mathrm{X}_{1}\right)$ sebesar 0,141 menunjukkan bahwa jika skor variabel kepatuhan meningkat sebesar satu, maka skor kepuasan nasabah Unit Usaha Syariah meningkat sebesar 0,141 dengan asumsi variabel lain konstan. Koefisien variabel jaminan $\left(\mathrm{X}_{2}\right)$ sebesar 0,172 menunjukkan bahwa jika skor jaminan meningkat satu, maka skor kepuasan nasabah tabungan Unit Usaha Syariah meningkat sebesar 0,172. Koefisien variabel keandalan $\left(\mathrm{X}_{3}\right)$ sebesar 0,196 menunjukkan bahwa jika skor variabel jaminan meningkat satu, maka skor kepuasan nasabah tabungan Unit Usaha Syariah meningkat sebesar 0,196. Koefisien variabel bukti fisik $\left(\mathrm{X}_{4}\right)$ sebesar -0,128 menunjukkan bahwa jika skor variabel bukti fisik meningkat satu, maka skor kepuasan nasabah tabungan Unit Usaha Syariah berkurang sebesar 0,128. Hal ini mengindikasikan bahwa fasilitas fisik bukanlah menjadi faktor pertimbangan utama dalam menentukan kepuasan nasabah. Koefisien variabel empati $\left(\mathrm{X}_{5}\right)$ sebesar 0,335 menunjukkan bahwa jika skor variabel jaminan meningkat satu, maka skor kepuasan nasabah tabungan Unit Usaha Syariah meningkat sebesar 0,335. Koefisien variabel daya tanggap $\left(\mathrm{X}_{6}\right)$ sebesar 0,206 menunjukkan bahwa jika skor variabel jaminan meningkat satu, maka skor kepuasan nasabah tabungan Unit Usaha Syariah meningkat sebesar 0,206 . Berdasarkan nilai koefisien regresi dari enam variabel bebas yang digunakan dapat diketahui bahwa variabel 
empati memiliki koefisien regresi yang paling besar yaitu 0,335 . Hal ini menunjukkan bahwa variabel empati memiliki pengaruh yang paling besar terhadap kepuasan nasabah tabungan Unit Usaha Syariah Bank Jambi. Sedangkan variabel bukti fisik memiliki koefisien regresi yang paling kecil yaitu sebesar - 0,128. Hal ini menunjukkan bahwa fasilitas fisik bukanlah faktor dominan dalam menentukan tingkat kepuasan nasabah dalam menggunakan layanan jasa perbankandi Unit Usaha Syariah Bank Jambi.

Tabel 8

Model Summary

\begin{tabular}{|l|l|r|r|r|r|}
\hline Model & R & R Square & Adjusted R Square & Std. Error of the Estimate & Durbin-Watson \\
\hline 1 & $.694^{\mathrm{a}}$ & .482 & .449 & .49992 & 2.255 \\
\hline
\end{tabular}

Sumber: data olahan

Nilai koefisien determinasi $\mathrm{R}^{2}$ sebesar 0,482 menunjukkan bahwa 48,2 \% dari variasi yang terjadi pada variabel kepuasan nasabah tabungan Unit Usaha Syariah Bank Jambi dapat dijelaskan oleh variabel kualitas pelayanan yang terdiri dari kepatuhan, jaminan, keandalan, bukti fisik, empati dan daya tanggap sedangkan $51,8 \%$ sisanya dipengaruhi oleh variabel lain di luar model penelitian. Nilai koefisien korelasi R sebesar 0,694 menunjukkan bahwa antara variabel kualitas pelayanan dan kepuasan nasabah tabungan Unit Usaha Syariah Bank Jambi terdapat hubungan positif dan cukup erat.

Tabel 9

Annova

\begin{tabular}{|c|r|r|r|r|r|r|}
\hline \multicolumn{2}{|c|}{ Model } & Sum of Squares & df & Mean Square & \multicolumn{1}{c|}{ F } & Sig. \\
\hline \multirow{1}{*}{1} & Regression & 21.636 & 6 & 3.606 & 14.429 & $.000^{\mathrm{b}}$ \\
\cline { 2 - 7 } & Residual & 23.242 & 93 & .250 & & \\
\cline { 2 - 7 } & Total & 44.879 & 99 & & & \\
\hline
\end{tabular}

Sumber: data olahan

Hasil pengolahan data diketahui bahwa nilai Sig. sebesar $0,000<0,05$ (taraf signifikansi) yang berarti bahwa secara simultan variabel bebas tersebut berpengaruh signifikan terhadap kepuasan nasabah Unit Usaha Syariah Bank Jambi.

Tabel 10

Coefficients

\begin{tabular}{|c|c|c|c|c|c|c|c|c|}
\hline & \multirow{2}{*}{ Model } & \multicolumn{2}{|c|}{ Unstandardized Coefficients } & \multirow{2}{*}{$\begin{array}{c}\text { Standardized Coefficients } \\
\text { Beta }\end{array}$} & \multirow{2}{*}{$\mathrm{t}$} & \multirow{2}{*}{ Sig. } & \multicolumn{2}{|c|}{ Collinearity Statistics } \\
\hline & & B & Std. Error & & & & Tolerance & VIF \\
\hline \multirow[t]{7}{*}{1} & (Constant) & .254 & 357 & & .709 & .480 & & \\
\hline & Kepatuhan & .141 & .089 & .132 & 1.579 & .118 & .798 & 1.253 \\
\hline & Jaminan & .172 & .103 & .167 & 1.668 & .099 & .557 & 1.795 \\
\hline & Keandalan & .196 & .103 & .194 & 1.902 & .060 & .536 & 1.867 \\
\hline & Bukti Fisik & -.128 & .112 & -.122 & -1.141 & .257 & .487 & 2.055 \\
\hline & Empati & .335 & .108 & .320 & 3.110 & .002 & .526 & 1.902 \\
\hline & Daya Tanggap & .206 & .096 & .204 & 2.152 & .034 & .621 & 1.610 \\
\hline
\end{tabular}

Sumber: data olahan

Uji t digunakan untuk mengetahui pengaruh variabel bebas $\mathrm{X}$ terhadap variabel terikat $\mathrm{Y}$ secara parsial. Dengan menggunakan taraf signifikansi $5 \%(\alpha=0,05)$ diperoleh hasil uji t terhadap variabel bebas dalam penelitian ini sebagai berikut: variabel Kepatuhan $\left(\mathrm{X}_{1}\right)$ dari hasil uji t yang dilakukan diperoleh nilai Sig yang lebih besar dari 0,05 yaitu 0,118 . Hal ini berarti antara variabel kepatuhan dan kepuasan nasabah tidak terdapat pengaruh yang signifikan. Tidak signifikannya pengaruh variabel kepatuhan (Compliance) terhadap kepuasan nasabah tabungan Unit Usaha Syariah Bank Jambi dapat disebabkan karena yang menjadi nasabah tabungan Unit Usaha Syariah Bank Jambi tersebut tidak hanya dari golongan muslim tetapi terdapat juga nasabah non muslim sebanyak sekitar $20 \%$ dari total nasabah. Bagi nasabah non mslim tersebut kepatuhan pada hukum syariat Islam bukanlah menjadi alasan utama mereka untuk menggunakan jasa layanan perbankan syariah. Alasan nasabah non muslim tersebut menjadi nasabah pada Unit Usaha Syariah Bank Jambi lebih kepada keuntungan yang lebih besar secara materi yang mereka terima dibandingkan dengan bank konvensional. Variabel Jaminan $\left(\mathrm{X}_{2}\right)$, diperoleh nilai Sig yang lebih besar dari 0,05 yaitu 0,099. Hal ini berarti antara variabel jaminan dan kepuasan nasabah tidak terdapat pengaruh yang signifikan. Seadangkan Variabel Keandalan $\left(X_{3}\right)$ diperoleh nilai Sig yang lebih besar dari 0,05 yaitu 0,060, berarti antara variabel 
keandalan dan kepuasan nasabah tidak terdapat pengaruh yang signifikan. Variabel Bukti Fisik $\left(\mathrm{X}_{4}\right)$, dari hasil uji $\mathrm{t}$ diperoleh nilai Sig yang lebih besar dari 0,05 yaitu 0,257 artinya antara variabel bukti fisik dan kepuasan nasabah tidak terdapat pengaruh yang signifikan. Variabel Empati $\left(\mathrm{X}_{5}\right)$ diperoleh nilai Sig yang lebih kecil dari 0,05 yaitu 0,002 , artinya antara variabel empati dan kepuasan nasabah terdapat pengaruh yang signifikan. Hal ini menunjukkan bahwa adanya perhatian khusus dari pihak bank dan akses yang mudah dalam pelayanan nasabah menjadi pertimbangan penting dalam menentukan kepuasan nasabah tabungan Unit Usaha Syariah Bank Jambi. Variabel Daya Tanggap $\left(\mathrm{X}_{6}\right)$, diperoleh nilai Sig yang lebih kecil dari 0,05 yaitu 0,034. Berarti antara variabel empati dan kepuasan nasabah terdapat pengaruh yang signifikan. Hal ini menunjukkan bahwa nasabah menjadikan variabel daya tanggap seperti keramahan dan kemampuan untuk bertindak cepat dalam mengatasi keluhan nasabah sebagai faktor yang penting dalam menentukan kepuasan nasabah Unit Usaha Syariah Bank Jambi.

\section{Simpulan}

Kualitas Pelayanan Unit Usaha Syariah berada pada kategori sangat baik, untuk variabel kepatuhan, jaminan, keandalan, bukti fisik, empati dan daya tanggap, serta nasabah tabungan merasa sangat puas dengan pelayanan yang diberikan. Variabel kepatuhan, jaminan, keandalan dan bukti fisik tidak berpengaruh signifikan terhadap kepuasan nasabah tabungan Unit Usaha Syariah Bank Jambi, sedangkan variabel empati dan daya tanggap berpengaruh signifikan.

\section{Daftar Pustaka}

Danang, Sunyoto. (2014), Dasar-dasar Manajemen Pemasaran, Cetakan Ketiga, Jakarta: CAPS.

Danang, Sunyoto. (2015), Perilaku Konsumen Dan Pemasaran, Cetakan Pertama, Yogyakarta: CAPS.

Danang, Sunyoto. (2013), Teori, Kuesioner \& Analisis Data, Cetakan Pertama, Yogyakarta: Graha Ilmu.

Fauzi, Abu Umar. (2016), Mengukur Pengaruh Kualitas Layanan Model Carter Terhadap Kepuasan Nasabah Perbankan Syariah Indonesia, Jounal of Busiiness and Banking Perbankan Vol.6 No.2.

Kotler, Philip. \& Keller, Kevin L. (2009), Manajemen Pemasaran, Edisi 13, Jilid 1, Jakarta: Erlangga.

Sugiyono, (2011), Metode Penelitian Pendekatan Kuantitatif dan $R \& D$, Bandung : Alfabeta.

Umar, Husein.(2011), Metode Penelitian Untuk Skripsi Dan Tesis Bisnis, Edisi Ke-11, Jakarta: Rajawali Pers. 